\title{
EFICIÊNCIA DO USO DE TERRA DE DIATOMÁCEA NA PROTEÇÃO DE GRÃOS DE MILHO
}

Luidi Eric Guimarães Antunes', Paulo André da Rocha Petry², Paulo Ricardo de Jesus Rizzotto Junior ${ }^{3}$, Roberto

Gottardi ${ }^{4}$, Rafael Gomes Dionello ${ }^{5}$

\section{RESUMO}

Dentre os principais métodos de controle de insetos na pós-colheita de grãos, destaca-se o uso da terra de diatomácea. Desse modo, objetivou-se testar a eficiência de diferentes dosagens deste pó-inerte no controle de adultos de Sitophilus zeamais em grãos de milho, durante o armazenamento. Usaram-se cinco repetições com $100 \mathrm{~g}$ de grãos, com diferentes conteúdos de água (12, 14 e 17\%), infestados com 20 insetos, tratados em diferentes dosagens $(0,500,1500$ e 2500 g. $\left.\mathrm{t}^{-1}\right)$ em1 hora e 15 dias após a aplicação do produto Verificou-se a mortalidade dos insetos nos grãos,e analisouse dos grãos analisou a perda de peso, umidade e a análise tecnológica aos 60 dias após cada período de infestação. Não houve diferenças estatísticas entre as médias de mortalidade independente do tratamento e da umidade. Os tratamentos controles de todas as umidades apresentaram maiores perdas de peso em ambos os períodos de infestação. Maior conteúdo de água final foi verificada em grãos sem tratamento com valor inicial de 17\%. Maiores valores de grãos carunchados foram obtidos para grãos não tratados, independente do conteúdo de água e período de infestação. Conclui-se, assim, que o tratamento com terra de diatomácea é eficiente para o controle de $S$. zeamais e reduz os danos nos grãos de milho.

Palavras-chave: Sitophilus zeamais, pó-inerte, análise de defeitos

\section{ABSTRACT}

\section{EFFICIENCY OF THE USE OF DIATOMACEOUS EARTH IN CORN GRAIN PROTECTION}

Among the main methods of insect control on post-harvest grain, highlighted is the use of diatomaceous earth. Thus, it was proposed to test the efficiency of different dosages of this inert powder on control of Sitophilus zeamais adults in maize grains during storage. Five repetitions were performed with $100 \mathrm{~g}$ of grains with different moisture contents (12, 14, and 17\%), infested with 20 insects, and treated with different dosages $\left(0,500,1500\right.$ and $\left.2500 \mathrm{~g} . \mathrm{t}^{-1}\right)$ in $\mathrm{h}$ hours and 15 days after application of the product. Mortality of insects in the grains, loss of weight, humidity and technological analysis of grains was performed at 60 days after each period of infestation. There were no statistical differences between the averages of mortality regardless of the treatment and moisture content. The control treatments of all moistures presented greater weight losses in both periods of infestation. Higher moisture content was found in untreated grains with initial value of $17 \%$. Higher values of rotten grains were obtained for untreated grains, independent of the moisture content and infestation period. It was therefore concluded that the treatment with diatomaceous earth is effective for the control of S. zeamais and reduces damage to corn grains.

Keywords: Sitophilus zeamais, inert-powder, defect analysis

\section{Recebido para publicação em 18/06/2012. Aprovado em 13/08/2012.}

1 - Eng. Agrônomo, Doutorando em Fitotecnia, Professor Assistente, UERGS, Vacaria, RS.luidieric.antunes@gmail.com

2 - Estudante de Agronomia, UFRGS, Porto Alegre, RS. rocha.petry@ufrgs.br

3 - Estudante de Agronomia, UFRGS, Porto Alegre, RS. paulo_rizzotto@hotmail.com,

4 - Eng. Agrônomo, EMATER, Fontoura Xavier, RS.gottardi@yahoo.com.br,

5 - Eng. Agrônomo, Professor Adjunto, UFRGS, Porto Alegre, RS. rafdionello@hotmail.com 


\section{INTRODUÇÃOO}

O Brasil é o terceiro maior produtor mundial de milho, totalizando 69,48 milhões de toneladas na safra 2011/2012 (CONAB, 2013), com uma estimativa de colheita de aproximadamente 80 milhões de toneladas na safra 2012/2013. Foi o grão mais produzido no Brasil na safra de 2011/2012, ultrapassando a produção de soja, que vinha obtendo a maior produção no país nas últimas safras. Em função de sua ampla e diversa utilização e do grande impacto econômico e social, esta cultura representa grande parcela da produção de cereais no contexto mundial e atualmente é o cereal mais produzido no mundo (FAO/WHO, 2013). A produção mundial de milho triplicou entre os anos de 1960 e 2001, aumento que basicamente acompanhou o crescimento da população de suínos e aves, pois é um ingrediente básico das rações destes animais (USDA, 2011). Nos últimos seis anos a produção mundial média foi de 778,8 milhões de toneladas, enquanto que, na década de 1980, a média anual era de aproximadamente 450 milhões de toneladas, caracterizando um expressivo aumento na produção total deste grão no mundo (USDA, 2011; DEMARCHI, 2011).

Grãos podem ser infestados por insetos ainda no campo, durante o armazenamento, na industrialização, em armazéns, supermercados e em nível doméstico. A presença de insetos nos diferentes produtos agrícolas apresenta relevância econômica devido aos diferentes tipos de danos provocados ou pela contaminação de seus fragmentos, resultando em deságios e, em alguns casos, na recusa do produto na comercialização (PINTO JUNIOR, 2008).

Entre os principais insetos de grãos armazenados existe a espécie Sitophilus zeamais Motschulsky (Coleoptera: Curculionidae), uma praga primária interna capaz de danificar o grão ainda sadio cujo desenvolvimento nas fases imaturas (ovo, larva e pupa) ocorre no interior do grão (LORINI, 2008).

De acordo com Antunes et al. (2011b), é comum o uso de produtos químicos no controle de insetos em grãos armazenados,sendo estes de alta periculosidade e período de carência específico. Também, existem os métodos físicos de controle, como temperatura, radiação, pós-inertes, onde se destaca a terra de diatomácea (TD), como tratamento protetor dos grãos.

A TD é um pó inerte obtido a partir de depósitos sedimentares de dióxido de sílica de águas doces e salgadas (CHANBANG et al., 2007ab; LORINI, 2008). Entre as principais vantagens do uso de terra de diatomácea, pode-se citar que, quando utilizada na dosagem recomendada, não oferece riscos à saúde de quem consome os grãos ou outros seres vivos que venham a ter contato com os grãos tratados com este produto. Esse, por sua vez, fica livre de resíduos tóxicos e de contaminantes do meio ambiente. Por possuir ação inseticida altamente eficiente, a terra de diatomácea não compromete o controle de insetos ao longo do tempo. Este pó inerte é de fácil manuseio, não necessitando de equipamento específico quando aplicado (LORINI et al., 2001; 2008).

Desta forma, objetivou-se com este trabalho verificar a eficiência da terra de diatomácea em diferentes concentrações, aplicada em grãos de milho com diferentes conteúdos de água, na inibição dos danos causados por adultos de $S$. zeamais, durante o armazenamento.

\section{MATERIAL E MÉTODOS}

O experimento foi realizado em sala climatizada $\left(25 \pm 5{ }^{\circ} \mathrm{C} ; 60 \pm 5 \%\right.$ UR)no Departamento de Fitossanidade da Faculdade de Agronomia da Universidade Federal do Rio Grande do Sul.

Os insetos utilizados neste experimento foram oriundos de criação,nas mesmas condições do experimento,e mantidos em recipientes plásticos com tampa apresentando abertura vedada com tecido tipo voile, para permitir as trocas gasosas. Foram alimentados com grãos de milho(Zea mays, L.),com conteúdo de água de $13 \%$.

Estes grãos foram oriundos de lavoura experimental da Estação ExperimentalAgronômica/ UFRGS, localizada no $\mathrm{km} 47$ da BR 290, em

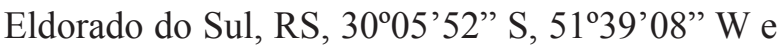
altitude média de $46 \mathrm{~m}$, sendo os mesmos livres de tratamentos com produtos químicos.

Os grãos utilizados, neste trabalho, foram de milho hibrido AS32, apresentando diferentes conteúdos de água.

Aplicou-se a TD em $18 \mathrm{~kg}$ de grãos de milho 
no total dos tratamentos, sendo $2 \mathrm{~kg}$ para cada tratamento. A aplicação ocorreu em bandejas retangulares, com homogeneização durante três minutos e o armazenamento em recipientes plásticos de $2 \mathrm{~L}$. Realizou-se esse procedimento manualmente com uso de luvas cirúrgicas, sendo um par para cada dosagem de TD, com o objetivo de evitar a presença de grãos sem o produto.

Os grãos de milho com conteúdos de água de, aproximadamente, 12, 14 e $17 \%$ em base úmida (b.u.) foram tratados com 500, 1500 e $2500 \mathrm{~g}$ de TD por tonelada de grãos, respectivamente. O controle constou de grãos sem tratamentos, ou seja, livres de TD. O produto utilizado foi da empresa Bernardo Química, doado pela Protection Insumos, com nome comercial Insecto $\AA$, contendo $86,7 \%$ de dióxido de sílica.

Cada tratamento foi composto por sete repetições, sendo colocados $100 \mathrm{~g}$ de grãos de milho em recipientes plásticos de $300 \mathrm{~mL}$, fechados com tecido tipo voile, juntamente com 20 adultos de $S$. zeamais, com idades variando de 20 a 50 dias, sem padronização sexual. Estes insetos foram identificados, com tinta têmpera, para evitar problemas nas verificações, devido às emergências de sua prole, ou mesmo, da prole já existente nos grãos, já que estes não foram expurgados.

Das sete repetições, cinco foram utilizadas para verificar a mortalidade dos insetos e realização da análise tecnológica ou de defeitos, as outras duas para determinar o conteúdo de água.

As infestações ocorreram em dois tempos distintos: 1 hora e 15 dias após a aplicação do produto nos grãos, com o intuito de verificar se ocorre alteração na eficiência da TD com maior tempo de contato com os grãos em relação aos insetos.

Os tratamentos foram armazenados por um período de 60 dias. Ao final deste período, realizou-se a análise tecnológica, também realizada nos grãos "in natura", para os três conteúdos de água estudados.

Cada lote de grãos apresentou inicialmente diferentes percentuais de grãos inteiros sendo $82,17 \%, 76,20$ e $82,24 \%$ para os grãos com $12 \%$, $14 \%$ e $17 \%$ de conteúdo de água, respectivamente.

A análise de defeitos compreende os parâmetros descritos na Portaria ${ }^{\circ} 11$ de 12 de abril de 1996, a qual se refere aos conceitos e classificação do milho (BRASIL, 1996). Os principais defeitos, segundo esta portaria, são:grãos carunchados, quebrados, chochos, fermentados, mofados, fragmentados, ardidos e brotados. Sendo que os cincos primeiros compreendem a categoria chamada grãos avariados.

A classificação quanto ao tipo de grãos compreende os seguintes parâmetros, conforme a mesma portaria:

- Tipo 1: constituído de milho seco com grãos regulares e conteúdo de água máximo de $14,5 \%$. Tolerância máxima de $1,5 \%$ de matérias estranhas, impurezas e fragmentos; $11 \%$ de grãos avariados, com máximo de 3\% de grãos ardidos e brotados (percentagem em peso);

- Tipo 2: constituído de milho seco, com grãos regulares e com umidade máxima de 14,5\%; Tolerância máxima de $2 \%$ de matérias estranhas, impurezas e fragmentos; $18 \%$ de grãos avariados, com máximo de $6 \%$ de grãos ardidos e brotados (percentagem em peso);

- Tipo 3: constituído de milho seco, com grãos regulares e com conteúdo de água máximo de $14,5 \%$. Tolerância máxima de $3 \%$ de matérias estranhas, impurezas e fragmentos; $27 \%$ de grãos avariados, com máximo de $10 \%$ de grãos ardidos e brotados (percentagem em peso).

- Abaixo do nível padrão de comercialização: mais de $27 \%$ de grãos avariados. O milho assim classificado poderá, conforme o caso, ser submetido ao rebeneficiamento.

Verificou-se também o peso inicial e final dos grãos de milho em cada repetição, com uso de balança de precisão de $0,01 \mathrm{~g}$, a emergência e a sobrevivência dos adultos em cada recipiente, através da sua contagem. Considerou-se como emergência qualquer adulto sem marcação.

Os dados obtidos foram submetidas à análise de variância e as médias comparadas pelo teste de Tukey a $1 \%$ de probabilidade,com uso do programa estatístico BioEstat 5.0 (AYRES et al., 2007).

\section{RESULTADO E DISCUSSÃO}

Com os grãos que apresentavam conteúdo de água de $12 \%$, os tratamentos controle, de ambos os períodos de infestação, apresentaram maiores valores de grãos avariados e diferiram estatisticamente tanto entre si como dos demais tratamentos (Quadro 1). 
Quadro 1. Valores médios de defeitos em grãos de milho (\%), com $12 \%$ de conteúdo de água, tratados com terra de diatomácea $\left(0,500,1500\right.$ e 2500 g.t $\left.^{-1}\right)$ e infestados com insetos adultos de Sitophilus zeamais, 1 hora e 15 dias após a aplicação, e posteriormente armazenados por 60 dias ( $25 \pm 5$ ${ }^{\circ} \mathrm{C} ; 60 \pm 5 \%$ UR).

\begin{tabular}{|c|c|c|c|c|c|c|c|c|c|}
\hline \multirow[b]{2}{*}{$\begin{array}{l}\operatorname{Dose}\left(\text { g.t }^{-1}\right) / \\
\operatorname{Danos}(\%)\end{array}$} & \multirow{2}{*}{$\begin{array}{c}\text { Inicial } \\
-- \\
\end{array}$} & \multicolumn{4}{|c|}{1 hora após a aplicação } & \multicolumn{4}{|c|}{15 dias após a aplicação } \\
\hline & & 0 & 500 & 1500 & 2500 & 0 & 500 & 1500 & 2500 \\
\hline $\begin{array}{l}\mathbf{G} \quad \mathbf{r} \quad \mathbf{a} \quad \mathbf{s} \\
\text { avariados }\end{array}$ & $\begin{array}{l}11,4 \\
\text { cd* }^{*}\end{array}$ & $41,21 \mathrm{a}$ & $19,88 \mathrm{c}$ & $16,2 \mathrm{~cd}$ & $17,43 \mathrm{~cd}$ & $34,44 \mathrm{~b}$ & $16,59 \mathrm{~cd}$ & $12,80 \mathrm{~d}$ & $13,93 \mathrm{~cd}$ \\
\hline Fragmentado & $3,66 \mathrm{a}$ & $0,48 \mathrm{~b}$ & $0,68 \mathrm{~b}$ & $0,37 \mathrm{~b}$ & $0,43 \mathrm{~b}$ & $0,65 \mathrm{~b}$ & $0,33 \mathrm{~b}$ & $0,33 \mathrm{~b}$ & $0,09 \mathrm{~b}$ \\
\hline Ardido & $0,76 \mathrm{~d}$ & $4,53 \mathrm{bcd}$ & $10,16 \mathrm{a}$ & $8,64 \mathrm{ab}$ & $6,98 \mathrm{abc}$ & $2,12 \mathrm{~cd}$ & 5,17 abcd & $3,76 \mathrm{bcd}$ & $3,40 \mathrm{~cd}$ \\
\hline Brotado & $0,64 \mathrm{~b}$ & $2,70 \mathrm{ab}$ & $4,88 \mathrm{a}$ & $3,67 \mathrm{ab}$ & $3,15 \mathrm{ab}$ & $3,93 \mathrm{ab}$ & $6,10 \mathrm{a}$ & $4,57 \mathrm{a}$ & $5,67 \mathrm{a}$ \\
\hline Impurezas & $1,37 \mathrm{ab}$ & $4,67 \mathrm{a}$ & $1,40 \mathrm{ab}$ & $0,70 \mathrm{~b}$ & $0,94 \mathrm{~b}$ & $1,06 \mathrm{~b}$ & $0,86 \mathrm{~b}$ & $0,53 \mathrm{~b}$ & $0,45 \mathrm{~b}$ \\
\hline Inteiro & $82,17 \mathrm{a}$ & $46,41 \mathrm{e}$ & $63,00 \mathrm{~cd}$ & $70,42 \mathrm{bc}$ & $71,07 \mathrm{bc}$ & $57,80 \mathrm{~d}$ & $70,95 \mathrm{bc}$ & $78,01 \mathrm{ab}$ & $76,46 \mathrm{ab}$ \\
\hline
\end{tabular}

*Médias seguidas de mesma letra na linha não diferem estatisticamente, pelo teste de Tukey, a 1\% de probabilidade. $0=$ tratamento controle.

Os elevados valores de grãos carunchados, que se enquadram dentro dos grãos avariados, nos tratamentos controle, ou seja, sem uso de TD $(31,75$ e $25,66 \%$ para 1 h e 15 dias, respectivamente), corroboram com o relatado por Antunes et al. (2011a), que, ao infestarem grãos de milho com conteúdo de água de $11,97 \%$ e livres de tratamentos com adultos de $S$. zeamais, verificaram aumento de $9,77 \%$ para essa categoria ao final de 60 dias de armazenamento, mostrando claramente que o uso de TD reduz o carunchamento dos grãos de milho.

Em outro trabalho, Antunes et al. (2011b), ao submeterem grãos de milho, com $12 \%$ de conteúdo de água, ao contato com adultos do gorgulho do milho, verificaram que, nos tratamentos controle, a presença de grãos carunchados aumentou, aos 60 dias de contato, em $4,38 \%$ e $9,13 \%$ para 1 hora e 10 dias de infestação, após aplicação de TD, respectivamente. Desta forma, os dados obtidos neste trabalho foram superiores aos encontrados por Antunes et al. (2011b).

Esse fato, provavelmente, esta relacionado à quantidade de insetos utilizados nos experimentos, enquanto os autores utilizaram 10 adultos por repetição com $100 \mathrm{~g}$ de grãos, neste trabalho utilizou-se 20 adultos para a mesma condição por repetição, ocasionando assim maiores médias de grãos carunchados. Mostrando claramente que quanto maior a quantidade de insetos infestando uma massa de grãos no armazenamento, maiores serão as quantidades de grãos carunchados, por consequência, aumentando a percentagem de grãos avariados.

Em relação aos grãos fragmentados (Quadro 1), todos os tratamentos de ambos os períodos de infestação apresentaram queda nos valores em relação aos grãos "in natura", 3,66\%. Isto está relacionado à alimentação dos insetos, que mesmo sendo primários,consumiram os fragmentos de grãos presentes no recipiente, assim como ao aumento de grãos ardidos (ANTUNES et al., 2011b). O fato de insetos primários atacarem os grãos inteiros não impede a sua alimentação, por grãos quebrados e/ou fragmentados.

As maiores médias de impurezas (Quadro 1) foram encontradas para os tratamentos "in natura",

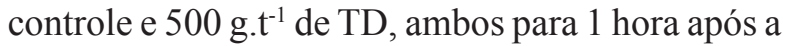
infestação, e diferiram estatisticamente dos demais resultados.

A maior média de grãos inteiros, $82,17 \%$, foi obtida no tratamento "in natura" e somente não diferiu estatisticamente dos tratamentos 1500 e 2500 g.t . $^{-1}$ de TD, ambos com infestação 15 dias após a aplicação. Esse resultado mostra que mesmo os grãos sendo tratados com TD não é garantia que a qualidade será totalmente mantida.

Classificando-se esses grãos conforme BRASIL (1996), os grãos "in natura" são do Tipo 2; os tratamentos 1500 e 2500 g.t. ${ }^{-1}$ de TD, ambos com infestação 15 dias após a aplicação, são do Tipo

\section{REVENG
509-519p.


3 e os demais tratamentos são classificados como abaixo do nível padrão de comercialização.

A redução da qualidade dos grãos mostra que, mesmo recebendo tratamento preventivo, o lote não está livre de danos causados por insetos, se estes conseguirem infestá-lo, e da presença de fungos, pois os maiores danos foram de grãos ardidos, seguidos de mofado e fermentados, mostrando que a presença de insetos facilita a entrada de fungos de armazenamento.

De acordo com Antunes et al. (2011b), grãos com conteúdo de água de $12 \%$, tratados com 1000 e 2000 g.t t $^{-1}$ de TD, tendem a sofrer diminuições de 3 a $4 \%$ na categorias de grãos inteiros, podendo, assim, permanecer na mesma tipificação em relação aos grãos "in natura", com a infestação ocorrendo $1 \mathrm{~h}$ após a aplicação.

Neste trabalho ocorreu uma diminuição de $14,30 \%$ para o tratamento 1500 g.t t $^{-1}$ de TD, dose intermediária entre as utilizadas pelos autores (op. cit.), e $13,51 \%$ para o tratamento 2500 g.t t $^{-1}$ de TD, dose superior às utilizadas pelos autores (op. cit.). Desta forma, a diferença observada pode estar relacionada à quantidade de insetos infestantes, 20 nesse experimento e 10 adultos no experimento dos autores.

Quando analisadas as médias obtidas para os grãos com $14 \%$ de conteúdo de água, verificase que os tratamentos controle, apresentaram os maiores valores para grãos carunchados $(34,72$ e $25,03 \%$ para 1 hora e 15 dias após a aplicação, respectivamente) e diferiram estatisticamente tanto entre si como dos demais tratamentos. Mostrando que ocorreu o efeito do tempo de infestação, ou seja, a terra de diatomácea apresenta um efeito ao longo do tempo de armazenamento dos grãos, conforme mencionado por Lorini (2008).

$\mathrm{O}$ tratamento "in natura" foi o que apresentou o maior valor de grãos fragmentados $(4,00 \%)$ e diferiu estatisticamente dos demais, os quais não diferiram entre si. Esta redução no percentual de grãos fragmentados provavelmente está relacionada ao aumento dos grãos ardidos verificados nos tratamentos com e sem TD, mostrados na Quadro 2. O Grão fragmentado apresenta uma maior possibilidade de ataque de fungos, e, por, consequência o aparecimento de grãos ardidos.

O tratamento 1500 g.t $^{-1}$ de TD, com a infestação sendo realizada 1 hora após a aplicação, apresentou a maior média, $2,76 \%$, para grãos fermentados e diferiu de grãos "in natura" e o controle no mesmo tempo de infestação, apresentando valores de 0,00 e $0,42 \%$, respectivamente.

Esse aumento de grãos fermentados não corrobora com o relatado por Antunes et al. (2011b), os quais não verificaram a presença de grãos fermentados ao término de 60 dias após o contato com os insetos.Esta diferença pode estar relacionada à quantidade de adultos utilizados, 20 por esses autores e 10 neste experimento.

Quadro 2. Valores médios (\%) de defeitos em grãos de milho, $14 \%$ de conteúdo de água, "in natura" e tratados sem e com terra de diatomácea $\left(0,500,1500\right.$ e 2500 g.t. . $\left.^{-1}\right)$, infestados com insetos adultos de Sitophilus zeamais, 1 hora e 15 dias após a aplicação, e posteriormente armazenados por 60 dias $\left(25 \pm 5^{\circ} \mathrm{C} ; 60 \pm 5 \%\right.$ UR $)$.

\begin{tabular}{lccccccccc}
\hline & Inicial & \multicolumn{4}{c}{ Infestação 1 hora após a aplicação } & \multicolumn{4}{c}{ Infestação 15 dias após a aplicação } \\
\cline { 2 - 9 } $\begin{array}{l}\text { D o s e }\left(\mathbf{g . t} \mathbf{t}^{-1}\right) / \\
\text { Danos (\%) }\end{array}$ & --- & 0 & 500 & 1500 & 2500 & 0 & 500 & 1500 & 2500 \\
\hline $\begin{array}{l}\text { G r a a o } \\
\text { avariados }\end{array}$ & $14,02 \mathrm{e}^{*}$ & $47,57 \mathrm{a}$ & $26,36 \mathrm{bc}$ & $24,93 \mathrm{bc}$ & $30,84 \mathrm{~b}$ & $30,93 \mathrm{~b}$ & $22,53 \mathrm{~cd}$ & $21,56 \mathrm{~cd}$ & $17,59 \mathrm{de}$ \\
Fragmentado & $4,00 \mathrm{a}$ & $0,55 \mathrm{~b}$ & $0,22 \mathrm{~b}$ & $0,22 \mathrm{~b}$ & $0,48 \mathrm{~b}$ & $0,52 \mathrm{~b}$ & $0,27 \mathrm{~b}$ & $0,24 \mathrm{~b}$ & $0,51 \mathrm{~b}$ \\
Ardido & $2,16 \mathrm{c}$ & $10,81 \mathrm{a}$ & $2,68 \mathrm{bc}$ & $5,12 \mathrm{bc}$ & $8,22 \mathrm{abc}$ & $12,65 \mathrm{a}$ & $8,60 \mathrm{ab}$ & $12,35 \mathrm{a}$ & $7,87 \mathrm{ab}$ \\
Brotado & $0,00 \mathrm{~b}$ & $0,51 \mathrm{ab}$ & $0,84 \mathrm{ab}$ & $1,54 \mathrm{a}$ & $1,51 \mathrm{a}$ & $1,51 \mathrm{a}$ & $1,08 \mathrm{a}$ & $1,25 \mathrm{a}$ & $0,70 \mathrm{ab}$ \\
Impurezas & $3,62 \mathrm{ab}$ & $4,61 \mathrm{a}$ & $2,71 \mathrm{ab}$ & $3,29 \mathrm{ab}$ & $2,94 \mathrm{ab}$ & $1,30 \mathrm{~b}$ & $1,20 \mathrm{~b}$ & $1,31 \mathrm{~b}$ & $1,57 \mathrm{ab}$ \\
Inteiro & $76,20 \mathrm{a}$ & $35,95 \mathrm{~d}$ & $67,19 \mathrm{a}$ & $64,90 \mathrm{a}$ & $56,01 \mathrm{bc}$ & $53,09 \mathrm{c}$ & $66,32 \mathrm{a}$ & $63,29 \mathrm{ab}$ & $71,76 \mathrm{a}$ \\
\hline
\end{tabular}

*Médias seguidas de mesma letra na linha não diferem estatisticamente, pelo teste de Tukey, a $1 \%$ de probabilidade. 
Para a categoria impurezas, o maior valor, $4,61 \%$, foi encontrado no tratamento controle, infestados 1 hora após a aplicação, diferindo dos tratamentos controle, 500 e 1500 g.t $^{-1}$ de TD, infestados 15 dias após a aplicação.

A menor média de grãos inteiros, $35,95 \%$, foi verificada para o tratamento controle,infestados 1 hora após a aplicação, e diferiu estatisticamente dos demais tratamentos. Novamente, grãos "in natura" apresentaram a maior média, $76,20 \%$, nesta categoria.

Classificando-se esses grãos conforme BRASIL (1996), os grãos “in natura" são do Tipo 3 e demais tratamentos são classificados como abaixo do nível padrão de comercialização. Esta classificação pode estar relacionada à forma como o lote foi armazenado, na qual a umidade era elevada, o que pode explicar elevadas médias de grãos mofados em todos os tratamentos, assim como a ocorrência de fungos e o aumento de grãos ardidos, visto que o objetivo principal do uso de terra de diatomácea é o controle de insetos e não de fungos. Em geral, o uso de TD diminui com o aumento da umidade relativa e o conteúdo de água dos grãos, mas aumenta com a temperatura (STATHERS, 2004).

De acordo com Antunes et al. (2011b), grãos com conteúdo de água de 14\%, tratados com 1000 e 2000 g.t t $^{-1}$ de TD, tendem a sofrer diminuições de 3 a 5\% na categorias de grãos inteiros, podendo assim permanecer na mesma tipificação em relação aos grãos, "in natura". Neste trabalho, a diminuição foi de $11,22 \%$ para o tratamento 1500 g.t $t^{-1}$ de TD, dose intermediária entre as utilizadas pelos autores, e $20,11 \%$ para o tratamento 2500 g. $\mathrm{t}^{-1}$ de TD, dose superior às utilizadas pelos autores. Desta forma, a diferença observada, está relacionada à quantidade de insetos infestantes, 20 nesse experimento e 10 adultos no experimento dos autores.

No lote de grãos apresentando $17 \%$ de conteúdo de água, as maiores médias de grãos carunchados $(42,54$ e $34,05 \%$ para 1 hora e 15 dias após a aplicação, respectivamente) foram verificadas para ambos os tratamentos controle, os quais diferiram estatisticamente tanto entre si como dos demais tratamentos. Mostrando mais uma vez que ocorreu o efeito do tempo de infestação, conforme já observado por Lorini (2008).

Conforme o verificado nos demais conteúdos de água avaliados, grãos "in natura" apresentaram a maior média de grãos fragmentados $(3,88 \%)$ e diferiu dos demais tratamentos. Novamente esse fato está relacionado ao aumento dos grãos ardidos nos tratamentos.

A maior média de grãos fermentados $(5,68 \%)$ foi verificada no tratamento 500 g. $\mathrm{t}^{-1}$ de TD infestados após 15 dias da aplicação e somente não diferiu dos tratamentos 1500 e 2500 g.t $^{-1}$ de TD infestados 1 hora e 15 dias após a aplicação, respectivamente. O tratamento controle, infestados 1 hora após a aplicação, apresentou a maior média de impurezas, $3,96 \%$, e diferiu estatisticamente dos demais tratamentos. Os tratamentos controle de ambos os

Quadro 3. Valores médios (\%) de defeitos em grãos de milho, $17 \%$ de conteúdo de água, "in natura" e tratados sem e com terra de diatomácea $\left(0,500,1500\right.$ e 2500 g.t . $\left.^{-1}\right)$, infestados com insetos adultos de Sitophilus zeamais 1 hora e 15 dias após a aplicação, armazenados por 60 dias $(25 \pm$ $5{ }^{\circ} \mathrm{C} ; 60 \pm 5 \%$ UR).

\begin{tabular}{lccccccccc}
\hline & Inicial & \multicolumn{3}{c}{ Infestação 1 hora após a aplicação } & \multicolumn{4}{c}{ Infestação 15 dias após a aplicação } \\
\cline { 2 - 10 } $\begin{array}{l}\text { Dos e (g.t } \\
\text { Danos (\%) }\end{array}$ & --- & 0 & 500 & 1500 & 2500 & 0 & 500 & 1500 & 2500 \\
\hline $\begin{array}{l}\text { G r a a o } \\
\text { avariados }\end{array}$ & $11,92 \mathrm{~d}^{*}$ & $51,11 \mathrm{a}$ & $17,43 \mathrm{~cd}$ & $15,85 \mathrm{~cd}$ & $12,64 \mathrm{~d}$ & $44,45 \mathrm{~b}$ & $20,46 \mathrm{c}$ & $14,43 \mathrm{~cd}$ & $16,16 \mathrm{~cd}$ \\
Fragmentado & $3,88 \mathrm{a}$ & $1,01 \mathrm{~b}$ & $0,82 \mathrm{~b}$ & $0,52 \mathrm{~b}$ & $1,01 \mathrm{~b}$ & $0,84 \mathrm{~b}$ & $0,69 \mathrm{~b}$ & $0,81 \mathrm{~b}$ & $0,41 \mathrm{~b}$ \\
Ardido & $0,45 \mathrm{~b}$ & $3,28 \mathrm{a}$ & $3,00 \mathrm{ab}$ & $3,06 \mathrm{ab}$ & $1,91 \mathrm{ab}$ & $1,16 \mathrm{ab}$ & $2,56 \mathrm{ab}$ & $1,06 \mathrm{ab}$ & $1,37 \mathrm{ab}$ \\
Brotado & $0,12 \mathrm{a}$ & $0,61 \mathrm{a}$ & $0,25 \mathrm{a}$ & $0,45 \mathrm{a}$ & $0,38 \mathrm{a}$ & $0,19 \mathrm{a}$ & $0,45 \mathrm{a}$ & $0,47 \mathrm{a}$ & $0,47 \mathrm{a}$ \\
Impurezas & $1,38 \mathrm{bc}$ & $3,96 \mathrm{a}$ & $2,78 \mathrm{~b}$ & $1,45 \mathrm{bc}$ & $2,00 \mathrm{bc}$ & $1,26 \mathrm{bc}$ & $0,87 \mathrm{c}$ & $1,06 \mathrm{c}$ & $0,72 \mathrm{c}$ \\
Inteiro & $82,24 \mathrm{a}$ & $40,03 \mathrm{c}$ & $75,72 \mathrm{a}$ & $78,67 \mathrm{a}$ & $82,06 \mathrm{a}$ & $52,10 \mathrm{~b}$ & $74,97 \mathrm{a}$ & $82,17 \mathrm{a}$ & $80,87 \mathrm{a}$ \\
\hline
\end{tabular}

*Médias seguidas de mesma letra na linha não diferem estatisticamente, pelo teste de Tukey, a 1\% de probabilidade. 
períodos de infestação apresentaram as menores médias de grãos inteiros $(40,03$ e $52,10 \%$ para 1 hora e 15 dias após a aplicação, respectivamente) e diferiram estatisticamente tanto entre si como dos demais tratamentos, os quais foram similares (Quadro 3). Classificando-se esses grãos conforme BRASIL (1996), os grãos "in natura", 2500 g.t t $^{-1}$ de TD para infestação de 1 hora e 1500 g.t $t^{-1}$ de TD para infestação com 15 dias são do Tipo 2; $500 \mathrm{e}$ 1500 g.t $\mathrm{t}^{-1}$ de TD para infestação de 1 hora, $500 \mathrm{e}$ 2500 g.t t $^{-1}$ de TD para infestação com 15 dias, são do Tipo 3; demais tratamentos são classificados como abaixo do nível padrão de comercialização.

Analisando os três conteúdos de água avaliados, percebe-se que a categoria de grãos carunchados sempre apresentou maior valor no tratamento controle para os grãos infestados com 1 hora após a aplicação. Esse fato pode estar relacionado à diferença de tempo entre as infestações, onde,sem a presença de insetos, a troca de água dos grãos com o ambiente é facilitada, ou seja, uma redução no conteúdo de água nos grãos em função da tendência de entrarem em equilíbrio higroscópico com o ambiente de armazenamento.

Analisando as médias de perda de peso para todos os lotes com a infestação ocorrendo 1 hora após a aplicação, observa-se que as menores médias, 88,$15 ; 83,78$ e $81,62 \mathrm{~g}$, de peso final, ou seja, as maiores perdas, foram verificadas para o tratamento controle de cada conteúdo de água estudado, 12; 14 e 17\%, respectivamente (Quadro 4).

Podemos observar que para os grãos infestados sem uso de TD, estas perdas em 60 dias de armazenamento variaram de $18,38 \%$, para os grãos armazenados com conteúdo de água de $17 \%$ e $11,85 \%$, para os grãos armazenados com conteúdo de água de $12 \%$. Também se pode observar que quanto maior o conteúdo de água nos grãos, maiores são as perdas nos tratamentos testemunhas. Segundo Athiée Paula (2002), grãos com conteúdo de água de, aproximadamente, $12 \%$ dificultam o desenvolvimento de insetos, ou seja, o lote com $17 \%$ de conteúdo de água estaria favorecendo o ataque de insetos.

Nos três conteúdos de água estudados, se observou diferença estatística entre o controle e os tratamentos com TD, os quais não diferiram entre si dentro de cada conteúdo de água, mostrando que, mesmo ocorrendo aumento de danos nos grãos, a diminuição do peso dos grãos é estatisticamente igual. Porém, ao se comparar com o peso inicial, este apresentou sempre os maiores valores e diferiu de todos os tratamentos em todas os conteúdos de água avaliados.

O tratamento 2500 g.t $\mathrm{t}^{-1}$ de TD foi o único a apresentar diferença estatística entre os lotes 12 e $17 \%$. Mesmo o lote $17 \%$ apresentando maior percentual de grãos inteiros $(82,06 \%)$ do que o lote $12 \%(71,07 \%)$, ainda apresentou menor peso $(92,40 \mathrm{~g})$, isto pode estar relacionado ao interior dos grãos, que pode ter sido mais consumido por larvas de S. zeamais, já que apresentava maior conteúdo de água.

Analisando a perda de peso de sete variedades

Quadro 4. Perda de peso (g) de grãos de milho infestados com adultos de Sitophilus zeamais avaliada após 60 dias, em função de infestação realizada 1 hora após a aplicação das dosagens de terra de diatomácea $\left(0,500,1500\right.$ e 2500 g.t $\left.t^{-1}\right) .\left(25 \pm 5{ }^{\circ} \mathrm{C} ; 60 \pm 5 \%\right.$ UR).

\begin{tabular}{lcccccc}
\hline & \multicolumn{2}{c}{$\mathbf{1 2 \%}$} & \multicolumn{2}{c}{$\mathbf{1 4 \%}$} & \multicolumn{2}{c}{$\mathbf{1 7 \%}$} \\
\cline { 2 - 7 } Dose (g.t $\left.{ }^{-1}\right)$ & Inicial $(\mathrm{g})$ & Final $(\mathrm{g})$ & Inicial $(\mathrm{g})$ & Final $(\mathrm{g})$ & Inicial $(\mathrm{g})$ & Final $(\mathrm{g})$ \\
\hline 0 & $100,05 \mathrm{~A} *$ & $88,15 \mathrm{Bb}$ & $100,07 \mathrm{~A}$ & $83,78 \mathrm{BCb}$ & $100,05 \mathrm{~A}$ & $81,62 \mathrm{Cb}$ \\
500 & $100,04 \mathrm{~A}$ & $95,03 \mathrm{Ba}$ & $100,04 \mathrm{~A}$ & $91,91 \mathrm{Ba}$ & $100,05 \mathrm{~A}$ & $92,69 \mathrm{Ba}$ \\
1500 & $100,04 \mathrm{~A}$ & $95,73 \mathrm{Ba}$ & $100,05 \mathrm{~A}$ & $93,37 \mathrm{Ba}$ & $100,04 \mathrm{~A}$ & $93,62 \mathrm{Ba}$ \\
2500 & $100,05 \mathrm{~A}$ & $97,14 \mathrm{Ba}$ & $100,04 \mathrm{~A}$ & $94,83 \mathrm{BCa}$ & $100,05 \mathrm{~A}$ & $92,40 \mathrm{Ca}$ \\
\hline $\mathrm{CV}^{* *}(\%)$ & 0,002 & 0,044 & 0,002 & 0,050 & 0,002 & 0,060 \\
\hline
\end{tabular}

*Médias seguidas de mesma letra na maiúscula na linha e minúscula na coluna não diferem estatisticamente, pelo teste de Tukey, a $1 \%$ de probabilidade.

** CV (\%): coeficiente de variação 
de milho, submetidas ao ataque de 20 adultos de $S$. zeamais, Almeida Filho et al. (2002) verificaram que aos 60 dias após a infestação, as perdas variam de 2,68 a 4,96 g. Esses autores utilizaram grãos livres de tratamentos.

Com a infestação ocorrendo aos 15 dias após a aplicação dos produtos, novamente as menores médias foram verificadas para os tratamentos controle dos três conteúdos de água avaliados $(92,27 ; 88,29$ e 85,12 g para $12 ; 14$ e $17 \%$, respectivamente) (Quadro 5).

Novamente verifica-se que as maiores perdas de peso ocorreram nos tratamentos controle, porém com $12 \%$ de conteúdo de água não ocorreu diferença estatística entre o controle e 500 g.t ${ }^{-1}$ de TD.

Com esse período de infestação, ocorreram diferenças estatísticas entre todos os tratamentos do lote $12 \%$ com o de $17 \%$, dentro das mesmas doses de TD. Este fato ocorreu em função do teor de água ter favorecido a presença de insetos no interior desses grãos, ocasionando uma maior perda em relação ao tratamento com conteúdo de água de $12 \%$. Mais uma vez, comprovando o que observaram Athiée Paula (2002), grãos mais secos estão menos propícios ao ataque de pragas, e, consequentemente, as perdas de peso são menores que em grãos mais úmidos.

Em relação à variação no conteúdo de água obtido ao final do experimento, verificou-se que todos os tratamentos apresentaram diminuição em relação ao valor inicial e com diferenças estatísticas (Quadro 6).

Quadro 5. Perda de peso (g) de grãos de milho infestados com adultos de Sitophilus zeamais avaliada após 60 dias, em função de infestação realizada 15 dias após a aplicação das dosagens de terra de diatomácea $\left(0,500,1500\right.$ e 2500 g.t. $\left.\mathrm{t}^{-1}\right) .\left(25 \pm 5{ }^{\circ} \mathrm{C} ; 60 \pm 5 \%\right.$ UR $)$.

\begin{tabular}{lcccccc}
\hline & \multicolumn{2}{c}{$\mathbf{1 2 \%}$} & \multicolumn{2}{c}{$\mathbf{1 4 \%}$} & \multicolumn{1}{c}{$\%$} \\
\cline { 2 - 7 } Dose (g.t $\left.\mathbf{t}^{-1}\right)$ & Inicial $(\mathrm{g})$ & Final $(\mathrm{g})$ & Inicial $(\mathrm{g})$ & Final $(\mathrm{g})$ & Inicial $(\mathrm{g})$ & Final $(\mathrm{g})$ \\
\hline 0 & $100,04 \mathrm{~A} *$ & $92,27 \mathrm{Ab}$ & $100,05 \mathrm{~A}$ & $88,29 \mathrm{Cb}$ & $100,03 \mathrm{~A}$ & $85,12 \mathrm{Cb}$ \\
500 & $100,00 \mathrm{~A}$ & $94,37 \mathrm{Bab}$ & $100,04 \mathrm{~A}$ & $93,02 \mathrm{BCa}$ & $100,02 \mathrm{~A}$ & $90,41 \mathrm{Ca}$ \\
1500 & $100,05 \mathrm{~A}$ & $96,46 \mathrm{Ba}$ & $100,05 \mathrm{~A}$ & $92,59 \mathrm{Ca}$ & $100,05 \mathrm{~A}$ & $92,98 \mathrm{Ca}$ \\
2500 & $100,05 \mathrm{~A}$ & $96,93 \mathrm{Ba}$ & $100,05 \mathrm{~A}$ & $94,50 \mathrm{Ba}$ & $100,02 \mathrm{~A}$ & $91,23 \mathrm{Ca}$ \\
\hline $\mathrm{CV}^{* *}(\%)$ & 0,003 & 0,024 & 0,001 & 0,029 & 0,001 & 0,034 \\
\hline
\end{tabular}

*Médias seguidas de mesma letra na maiúscula na linha e minúscula na coluna não diferem estatisticamente, pelo teste de Tukey, a $1 \%$ de probabilidade.

** CV (\%): coeficiente de variação

Quadro 6. Conteúdo de água (\%) inicial e final de grãos de milho submetidos à infestação de adultos de Sitophilus zeamais, avaliada após 60 dias, em função do tempo de infestação e das dosagens de terra de diatomácea $\left(0,500,1500\right.$ e 2500 g.t $\left.^{-1}\right) .\left(25 \pm 5^{\circ} \mathrm{C} ; 60 \pm 5 \%\right.$ UR $)$.

\begin{tabular}{|c|c|c|c|c|c|c|}
\hline \multirow[b]{2}{*}{$\begin{array}{l}\left.\text { Dose (g.t }{ }^{-1}\right) \text { / } \\
\text { Infestação }\end{array}$} & \multicolumn{5}{|c|}{ Conteúdo de água (\%) } & \multirow[b]{2}{*}{$C V * *(\%)$} \\
\hline & Inicial & 0 & 500 & 1500 & 2500 & \\
\hline 1 hora & $12,57 a^{*}$ & $11,87 \mathrm{~b}$ & $11,03 \mathrm{c}$ & $11,23 \mathrm{c}$ & $11,09 \mathrm{c}$ & 0,037 \\
\hline 15 dias & $12,57 \mathrm{a}$ & $11,09 \mathrm{~b}$ & $11,18 \mathrm{~b}$ & $11,20 \mathrm{~b}$ & $10,73 \mathrm{~b}$ & 0,027 \\
\hline 1 hora & $14,01 \mathrm{a}$ & $13,00 \mathrm{~b}$ & $11,36 \mathrm{c}$ & $10,53 \mathrm{~d}$ & $11,08 \mathrm{c}$ & 0,083 \\
\hline 15 dias & $14,01 \mathrm{a}$ & $12,75 \mathrm{~b}$ & $11,39 \mathrm{c}$ & $11,19 \mathrm{c}$ & $12,50 \mathrm{~b}$ & 0,097 \\
\hline 1 hora & $17,50 \mathrm{a}$ & $10,83 \mathrm{c}$ & $11,52 \mathrm{~b}$ & $11,20 \mathrm{bc}$ & $11,36 \mathrm{bc}$ & 0,033 \\
\hline 15 dias & $17,50 \mathrm{a}$ & $12,81 \mathrm{~b}$ & $11,35 \mathrm{c}$ & $11,21 \mathrm{c}$ & $11,28 \mathrm{c}$ & 0,062 \\
\hline
\end{tabular}

*Médias seguidas de mesma letra na linha não diferem estatisticamente, pelo teste de Tukey, a 1\% de probabilidade. ** CV (\%): coeficiente de variação 
Pode-se observar que os grãos tenderam ao equilíbrio higroscópico para a maioria dos tratamentos em conteúdos de água variando entre 11 e 12\%. Segundo Brooker et al. (1992), grãos de milho em condições de temperatura de $25{ }^{\circ} \mathrm{C}$ e UR de $60 \%$ apresentam equilíbrio higroscópico com conteúdo de água de $12,3 \%$, podendo variar em função da variedade. Estas foram às condições utilizadas durante o armazenamento dos grãos.

Este fato pode ser explicado pela capacidade de adsorção/umedecimento e dessorção/secagem dos grãos, visto que a capacidade de dessorção é até sete vezes maior do que a capacidade de adsorção, ou seja, é mais fácil retirar água dos grãos do que reidratá-los, o que pode ser visto em todos os tratamentos onde ocorreu uma redução no conteúdo de água, tendendo ao equilíbrio higroscópico, em função das condições do ambiente em que estão armazenados, conforme já observado por diversos autores (ALENCAR et al., 2009; ELIAS et al., 2008; ELIAS et al., 2009; SCHUH et al., 2011). As trocas de calor e água entre os grãos armazenados e o ar ambiente são dinâmicas e contínuas, até o limite de obtenção do equilíbrio higroscópico, em determinadas condições de temperatura e umidade relativa (ELIAS et al., 2009).

Quanto maior for à temperatura e menor a umidade relativa do ar, menor será a umidade de equilíbrio dos grãos. Portanto grãos que estão armazenados em ambientes com tendência ao equilíbrio higroscópico em conteúdos de água variando de 10 a $13 \%$, quando tratados com terra diatomácea apresentam alta taxa de mortalidade dos insetos, não importando o conteúdo de água inicial dos mesmos.

Analisando a mortalidade obtida ao final do experimento, verifica-se que todos os tratamentos diferiram estatisticamente dos controles, dentro de cada conteúdo de água avaliado, com exceção do tratamento 500 g.t . $^{-1}$ de TD do lote com $12 \%$ de conteúdo de água e quando a infestação ocorreu aos 15 dias após a aplicação em todos os tratamentos (Quadro 7).

Com o uso de TD, verifica-se que a média de mortalidade variou de 15,8 a 20,0 insetos, ou seja, de 79 a $100 \%$ em todos os tratamentos e conteúdos de água, porém sem ocorrência de diferenças estatísticas entre os mesmos (Quadro 7).

Desta forma, estes resultados não corroboram com os relados por Antunes et al. (2011b), que verificaram decréscimo na eficiência da TD em adultos de $S$. zeamais conforme aumenta o tempo em que ocorre a infestação após a aplicação do produto. Esses autores utilizaram 10 adultos, enquanto neste trabalho foram utilizados 20 , sendo assim, provavelmente essa diferença de insetos

Quadro 7. Número médio ( \pm EP) de adultos de Sitophilus zeamais avaliados mortos após 60 dias, em função do tempo de infestação, do conteúdo de água nos grãos de milho $(12,14$ e $17 \%)$ e das dosagens de terra de diatomácea (500, 1500 e 2000 g.t $\left.t^{-1}\right) .\left(25 \pm 5^{\circ} \mathrm{C} ; 60 \pm 5 \%\right.$ UR) $(\mathrm{n}=20)$.

\begin{tabular}{lcccccc}
\hline & \multicolumn{2}{c}{$\mathbf{1 2 \%}$} & \multicolumn{2}{c}{$\mathbf{1 4 \%}$} & \multicolumn{2}{c}{$\mathbf{1 7 \%}$} \\
\cline { 2 - 7 } $\begin{array}{l}\text { Infestaçã o/ } \\
\left.\text { Dose (g.t } \mathbf{t}^{-1}\right)\end{array}$ & 1 hora & 15 dias & 1 hora & 15 dias & 1 hora & 15 dias \\
\hline \multirow{2}{*}{0} & $11,8 \mathrm{~b}^{*}$ & $7,6 \mathrm{~b}$ & $7,2 \mathrm{~b}$ & $11,8 \mathrm{~b}$ & $16,8 \mathrm{a}$ & $15,0 \mathrm{a}$ \\
& $(\mathrm{EP} \pm 3,63)$ & $(\mathrm{EP} \pm 1,72)$ & $(\mathrm{EP} \pm 1,85)$ & $(\mathrm{EP} \pm 3,49)$ & $(\mathrm{EP} \pm 1,85)$ & $(\mathrm{EP} \pm 2,09)$ \\
500 & $15,8 \mathrm{a}$ & $20,0 \mathrm{a}$ & $20,0 \mathrm{a}$ & $20,0 \mathrm{a}$ & $20,0 \mathrm{a}$ & $16,6 \mathrm{a}$ \\
& $(\mathrm{EP} \pm 0,00)$ & $(\mathrm{EP} \pm 0,00)$ & $(\mathrm{EP} \pm 0,00)$ & $(\mathrm{EP} \pm 0,00)$ & $(\mathrm{EP} \pm 0,00)$ & $(\mathrm{EP} \pm 2,13)$ \\
1500 & $20,0 \mathrm{a}$ & $20,0 \mathrm{a}$ & $19,8 \mathrm{a}$ & $20,0 \mathrm{a}$ & $20,0 \mathrm{a}$ & $16,4 \mathrm{a}$ \\
& $(\mathrm{EP} \pm 0,00)$ & $(\mathrm{EP} \pm 0,00)$ & $(\mathrm{EP} \pm 0,02)$ & $(\mathrm{EP} \pm 0,00)$ & $(\mathrm{EP} \pm 0,00)$ & $(\mathrm{EP} \pm 2,22)$ \\
2500 & $20,0 \mathrm{a}$ & $19,6 \mathrm{a}$ & $20,0 \mathrm{a}$ & $20,0 \mathrm{a}$ & $20,0 \mathrm{a}$ & $20,0 \mathrm{a}$ \\
& $(\mathrm{EP} \pm 0,00)$ & $(\mathrm{EP} \pm 0,40)$ & $(\mathrm{EP} \pm 0,00)$ & $(\mathrm{EP} \pm 0,00)$ & $(\mathrm{EP} \pm 0,00)$ & $(\mathrm{EP} \pm 0,00)$ \\
\hline $\mathrm{CV} * *(\%)$ & 0,360 & 0,333 & 0,347 & 0,277 & 0,120 & 0,244 \\
\hline
\end{tabular}

*Médias seguidas de mesma letra na linha não diferem estatisticamente, pelo teste de Tukey, a $1 \%$ de probabilidade. ** CV (\%): coeficiente de variação 
presentes influenciou nos resultados, pois na mesma quantidade de grãos, $100 \mathrm{~g}$, havia diferentes quantidades de insetos, o que causa maior procura por alimento e assim facilita o contato com a TD. Mostrando claramente que quanto maior for à infestação maior é o controle.

Os resultados mostraram que indiferente do conteúdo de água nos grãos, ocorreu uma elevada mortalidade dos insetos, também devido à tendência de equilíbrio em conteúdos de água próximos a $12 \%$, que são umidades onde se tem maior eficiência deste produto..

Os resultados de $100 \%$ de mortalidades obtidas neste trabalho, em alguns tratamentos, foram semelhantes, ao registrado por Caneppele et al. (2010), os quais obtiveram $100 \%$ de mortalidade de $S$. zeamais, 30 insetos, com 750 g.t. te TD aos $^{-1}$ de 21 dias em milho com 14\% de conteúdo de água.

\section{CONCLUSÕES}

- Grãos livres de tratamentos de TD são facilmente danificados por insetos e aos 60 dias de contato são classificados como abaixo do nível padrão para comercialização. Maiores quantidades de grãos inteiros são verificadas nos lotes que tendem a perder mais água para entrar em equilíbrio higroscópico;

- Quanto melhor a qualidade inicial do lote, melhor é a proteção com o uso da terra de diatomácea. Indiferente do conteúdo de água do grão e da concentração de produto, a mortalidade de insetos foi elevada;

- Verificou-se tendência dos grãos entrarem em equilíbrio higroscópico, em função da temperatura e umidade relativa do local de armazenamento, em conteúdos de água variando de 10,53 a $13,00 \%$ b.u.;

- Os grãos não tratados apresentaram as maiores perdas de peso e menores mortalidades após 60 dias de armazenamento;

- O período de infestação não interfere no controle proporcionado pela terra de diatomácea nos adultos de $S$. zeamais.

\section{REFERÊNCIAS BIBLIOGRÁFICAS}

ALENCAR, E.R. DE; FARONI, L.R.D.; FILHO, A.F.L.; PETERNELLI, L.A.; COSTA, A.R. Qualidade dos grãos de soja armazenados em diferentes condições. Revista Brasileira de Engenharia Agrícola e Ambiental, v.13, n.5, p.606-613,2009.

ALMEIDA FILHO, A.J.; FONTES, L.S.; ARTHUR, V. Determinação da perda de peso do milho (Zea mays) provocada por Sitophilus oryzae e Sitophilus zeamais. Revista Ecossistema, v.27, n.12, p.41-44, 2002.

ANTUNES,L.E.G.;GATTARDI,R.;VIEBRANTZ, P.C.; DIONELLO, R.G. Características físicoquímicas de grãos de milho atacados por Sitophilus zeamais durante $\mathrm{o}$ armazenamento. Revista Brasileira de Engenharia Agrícola e Ambiental, v.15, n.6, p.615-620, 2011a.

ANTUNES, L.E.G.; FERRARI FILHO, E.; GATTARDI, R.; SANT'ANA, J.; DIONELLO, R.G. Avaliação do uso de terra de diatomácea contra a infestação de grãos de milho. Revista Brasileira de Ciências Agrárias, v.6, n.4, p.662669, $2011 b$.

ATHIÉ, I.; PAULA, C. Insetos de Grãos Armazenados Aspectos Biológicos e Identificação. São Paulo: Editora Varela, p.28-34, 2002.

AYRES, M.; AYRES, M. J.R.; AYRES, D.L.; dos SANTOS, A.S. BioEstat 5.0 Aplicações estatísticas nas áreas da ciências biológicas e médicas. Belém: Sociedade civil Mamirauá/ CNPq, 324p, 2007.

BRASIL. Ministério da Agricultura e Reforma Agrária. Portaria $\mathrm{N}^{\circ} 11$, de 12 de abril de 1996. Comissão Técnica de Normas e Padrões. Norma de Identidade, Qualidade, Embalagem e Apresentação do Milho. Brasília, 1996.

BROOKER, D.B.; BAKKER-ARKEMA, F.W.; HALL, C.W. Drying and storage of grains and oilseeds. New York: van Nostrand Reinhold, 450p, 1992. 
CANEPPELE, M.A.B.; ANDRADE, P.J.; SANTAELLA, A.G. Diferentes dosagens de pó inerte e temperaturas em milho armazenado para controle de gorgulho-do-milho. Scientia Agraria, v.11, n.4, p.343-347, 2010.

CHANBANG, Y.; ARTHUR, F.H.; WILDE, G.E.; THRONE, J.E. Efficacy of diatomaceous earth to control Rhyzopertha dominica (F.) (Coleoptera: Bostrichidae) in rough rice: Impacts of temperature and relative humidity. Crop Protection, n.26, p.923-929, 2007a.

CHANBANG, Y.; ARTHUR, F.H.; WILDE, G.E.; THRONE, J.E. Diatomaceous earth plusmethoprene for control of the lesser grain borer, Rhyzopertha dominica (F.) (Coleoptera:Bostrichidae) in rough rice. Journal of Stored Products Research, v.43, p.396-401, 2007b.

\section{COMPANHIA NACIONAL DE} ABASTECIMENTO (CONAB). Levantamentos de safra, 2013. Disponível em: $<$ http://www.conab. gov.br/conteudos.php? $\mathrm{a}=1253 \& \mathrm{t}=>$. Acesso em: 06/04/2013.

DEMARCHI, M. Análise Da Conjuntura Agropecuária Safra 2011/12: Milho. Secretaria Da Agricultura E Do Abastecimento Departamento De Economia Rural. Disponível em: < www. agricultura.pr.gov.br>. Acesso em: 05/04/2013.

ELIAS, M.C.; DIONELLO, R.G.; FORLIN, F.J.; OLIVEIRA, M.; GELAIN, J.; PETER, M.Z. Avaliação do uso de ácidos orgânicos na conservação de grãos de sorgo (Sorghum bicolor L. Moench) durante o armazenamento. Revista Semina: Ciências Agrárias, v.29, p.35-46, 2008.

ELIAS, M.C.; LOPES, V.; GUTKOSKI, L.C.; OLIVEIRA, M.; MAZZUTTI, S.; DIAS, A.R. G. Umidade de colheita, métodos de secagem e tempo de armazenamento na qualidade tecnológica de grãos de trigo (cv. 'Embrapa 16'). Ciência Rural,
Santa Maria, v.39, n.1, p.25-30, jan-fev, 2009.

FOOD AND AGRICULTURE ORGANIZATION - WORLD HEALTH ORGANIZATION (FAO/ WHO). FAO STAT-Agriculture Statistics 2013. Disponível em: < http://www.fao.org/corp/ statistics/en/ >. Acesso em: 04/04/2013.

LORINI, I. Manejo Integrado de Pragas de Grãos de Cereais Armazenados. EMBRAPA TRIGO, Passo Fundo, v.2, 72p, 2008.

LORINI, I.; FERREIRA FILHO, A.; BARBIERI, I.; DEMAMAN, N.A.; MARTINS, R.R.; DALBELLO, O. Terra de diatomáceas como alternativa no controle de pragas de milho armazenado em propriedade familiar. Agroecologia e Desenvolvimento Rural Sustentável, v.2, p.3236,2001

PINTO JUNIOR; A.R. Eficiência de terra de diatomáceas no controle de Sitophilus oryzae (L.), Cryptolestes ferrugineus (Stephens), Tribolium castaneum (Herbst) em milho armazenado a granel. Revista da Faculdade de Zootecnia, Veterinária e Agronomia(Uruguaiana), v.15, n.1, p.61-70, 2008.

SCHUH, G.; GOTTARDI, R.; FERRARI, E.F.; ANTUNES, L.E.G.; DIONELLO, R.G. Efeitos de dois métodos de secagem sobre a qualidade físico-química de grãos de milho safrinha-RS, armazenados por 6 meses.Semina: Ciências Agrárias, Londrina, v.32, n.1, p.235-244, 2011.

STATHERS, T.E.; DENNIFF, M.; GOLOB, P. The efficacy and persistence ofdiatomaceous earth admixed with commodity against four tropical stored product beetle pests.Journal of Stored Products Research, v.40, n.3, p.113-123,2004.

UNITED STATES DEPARTMENT OF AGRICULTURE (USDA) 2011. Disponível em: $<$ http://www.usda.gov/wps/portal/usda/usdahome >. Acesso em: 03/04/2013. 